\title{
“Mirror Image" Antagonists of Thrombin-induced Platelet Activation Based on Thrombin Receptor Structure
}

\author{
David T. Hung, ${ }^{\star \star}$ Thien-Khai H. Vu, ${ }^{\ddagger}$ Virginia I. Wheaton, ${ }^{\ddagger}$ Israel F. Charo, ${ }^{\star 5}$ Nicolas A. Nelken, ${ }^{ \pm \|}$ \\ Naomi Esmon," Charles T. Esmon, ${ }^{* *}$ and Shaun R. Coughlin ${ }^{\star *}$ \\ Department of *Medicine and "Surgery, and ${ }^{\ddagger}$ Cardiovascular Research Institute, University of California, San Francisco, \\ San Francisco, California 94143; ' Cor Therapeutics, Inc., South San Francisco, California 94080; and 'Oklahoma \\ Medical Research Foundation and ${ }^{* *}$ Howard Hughes Medical Institute, Oklahoma City, Oklahoma 73104
}

\begin{abstract}
Platelet activation by thrombin plays a critical role in hemostasis and thrombosis. Based on structure-activity studies of a cloned platelet thrombin receptor, we designed two "mirror image" antagonists of thrombin and thrombin receptor function. First, "uncleavable" peptides mimicking the receptor domain postulated to interact with thrombin were found to be potent thrombin inhibitors. Second, proteolytically inactive mutant thrombins designed to bind but not cleave the thrombin receptor were found to be specific antagonists of receptor activation by thrombin. The effectiveness of these designed antagonists in blocking thrombin-induced platelet activation suggests a model for thrombin-receptor interaction and possible strategies for the development of novel antithrombotic agents. ( $J$. Clin. Invest. 1992. 89:444-450.) Key words: active site mutants $\bullet$ inhibitor $\bullet$ peptide $\bullet$ serine proteases $\bullet$ thrombosis
\end{abstract}

\section{Introduction}

Thrombosis in arterial circulations is a leading cause of morbidity and mortality (1). Platelet activation by thrombin, a multifunctional serine protease evolved at sites of vascular injury, is believed to be a critical event in arterial thrombosis (2). We recently isolated a cDNA clone encoding a functional platelet thrombin receptor (3). The clone encodes a member of the seven transmembrane span family of receptors with a long amino-terminal extracellular extension that contains a thrombin cleavage site (LDPR/SFLL . . .; with/representing the point of cleavage). Carboxyl to the cleavage site lies the sequence DKYEPFWEDEE, which resembles the carboxyl tail of the leech anticoagulant hirudin; the carboxyl tail of hirudin is known to bind thrombin's anion-binding exosite (4). Structure-activity studies based on these observations suggest the following working model of thrombin-receptor interaction (3, $5,6)$. Thrombin recognizes its receptor by interacting with at least two sites: thrombin's S1-S4 subsites interact with the receptor's cleavage site (the LDPR sequence) and thrombin's anion-binding exosite interacts with the receptor's hirudin-like

Address reprint requests to Dr. Coughlin, Box 0524 HSW 846, University of California, San Francisco, San Francisco, CA 94143-0524. 1991.

Received for publication 26 May 1991 and in revised form 2 October

J. Clin. Invest.

(C) The American Society for Clinical Investigation, Inc.

0021-9738/92/02/0444/07 \$2.00

Volume 89, February 1992, 444-450
DKYEPFWEDEE sequence. Thrombin then activates its receptor by cleaving it at the LDPR/SFLL site, unmasking a new receptor amino terminus beginning with the sequence SFLL. . . . This new amino terminus then functions as a tethered peptide ligand, binding to an as yet undefined receptor domain and eliciting receptor activation (3). Based on this proteolytic model of thrombin receptor activation, we have produced two "mirror image" antagonists of thrombin and thrombin receptor function: $(a)$ "uncleavable" receptor-mimicking peptides designed to bind thrombin, preventing thrombin's interaction with its receptor and other substrates, and $(b)$ proteolytically inert mutant thrombins designed to bind but not activate the thrombin receptor, thereby preventing receptor interaction with and subsequent activation by native thrombin. The effectiveness of these antagonists supports the structure-activity relationships described above, further supports the notion that the cloned receptor mediates thrombin-induced platelet activation, and suggests possible strategies for the development of novel antithrombotic agents.

\section{Methods}

Materials. Purified human $\alpha$-thrombin was a generous gift from Dr. John W. Fenton II, Albany Medical College of Union University, Albany, NY. Peptides were made by the University of California, San Francisco Biomolecular Resource Center or were generously provided by Dr. Robert Scarborough, COR Therapeutics, Inc., South San Francisco, CA; peptides were high-pressure liquid chromatography (HPLC)-purified before use.

Preparation of active site mutant thrombins. Oligonucleotide-directed mutagenesis (7) was used to generate the appropriate active site residue substitutions (S205A and D99N/S205A) in a native prothrombin cDNA (8) cloned into a Bluescript SK-plasmid vector system (Stratagene Inc., La Jolla, CA). Successful introduction of the desired mutation(s) was confirmed by DNA sequencing. DNA coding for active site mutant or native prothrombins were subcloned into a pBJ1 expression vector (derived from pcDL SR $\alpha 296$ ) (9) and co-transfected into dihydrofolate reductase minus Chinese hamster ovary $(\mathrm{CHO})$ cells by lipofection (10) with a dihydrofolate reductase selection marker in pSV2D (11). Stable transfectants were isolated using nucleoside-deficient medium, and gene amplification was accomplished using $80 \mathrm{nM}$ methotrexate. Recombinant prothrombin production was determined by enzyme-linked immunosorbent assay (ELISA) and Western blots and the highest yielding clones were grown to confluence in a $24,000-\mathrm{cm}^{2}$ surface cell "factory" (Nunc, Inter Med, Naperville, IL) in minimum essential medium (MEM) $\alpha$-nucleoside-deficient medium with $80 \mathrm{nM}$ methotrexate, $100 \mathrm{U} / \mathrm{ml}$ penicillin, $100 \mu \mathrm{g} / \mathrm{ml}$ streptomycin, $25 \mathrm{mM}$ Hepes buffer, $5 \mu \mathrm{g} / \mathrm{ml}$ vitamin $\mathrm{K}, 0.2 \mathrm{mg} / \mathrm{ml}$ proline, and $10 \%$ dialyzed bovine calf serum. When the cultures reached full confluence, all medium was removed, all growing surfaces were washed six times with phosphate-buffered saline to remove contaminating bovine prothrombin and thrombin, and cells were grown in MEM $\alpha$-nucleoside-defi- 
cient medium containing $100 \mathrm{units} / \mathrm{ml}$ penicillin, $100 \mu \mathrm{g} / \mathrm{ml}$ streptomycin, $25 \mathrm{mM}$ Hepes buffer, $5 \mu \mathrm{g} / \mathrm{ml}$ vitamin $\mathrm{K}, 0.2 \mathrm{mg} / \mathrm{ml}$ proline, 1 $\mu \mathrm{g} / \mathrm{ml}$ insulin and $5 \mu \mathrm{g} / \mathrm{ml}$ transferrin for $36-48 \mathrm{~h}$. Recombinant S205A prothrombin was purified from conditioned media by anion exchange chromatography (12), diluted to $\sim 100 \mu \mathrm{g} / \mathrm{ml}$ in $150 \mathrm{mM}$ $\mathrm{NaCl}, 10 \mathrm{mM}$ Tris-HCl, pH 7.4, 0.5\% polyethylene glycol (PEG) 6000, and treated for $1 \mathrm{~h}$ with prothrombinase complex as previously described (13). $\mathrm{pH}$ was then changed to 7.0 with $1 \mathrm{M} \mathrm{HCl}$ and the S205A mutant thrombin-containing solution treated with an $\sim 1,000$ fold molar excess of ( $p$-amidinophenyl)methanesulfonyl fluoride (APMSF) $^{1}$ to inhibit factor Xa and any bovine thrombin that might contaminate the preparation. APMSF is a serine-dependent irreversible thrombin antagonist that rapidly inactivates native thrombin at $\mathrm{pH} 7.0$ but has a half-life of only $10^{-3} \mathrm{~s}$ at $\mathrm{pH} 8.0$ (14). For this reason, the $\mathrm{pH}$ of the APMSF-treated mutant thrombin preparation was then changed to 8.0 for $15 \mathrm{~min}$ to eliminate all APMSF. APMSF treatment inactivates native thrombin by modifying the active site serine but does not affect the "serine-less" mutant thrombin (see Fig. 2). The S205A mutant thrombin was then purified by anion exchange chromatography (12), identified by Western blot with anti-human thrombin antiserum, a goat antibody directed against reduced, carboxymethylated human $\alpha$-thrombin, at a 1:2,000 dilution. The concentration and purity of recombinant S205A thrombin preparations were determined by Coomassie and silver-stained SDS-PAGE gels. The mutant thrombin preparations used in these studies appeared homogeneous on silverstained SDS-PAGE gels.

To control for any residual APMSF remaining in the purified thrombin preparations after $\mathrm{pH} 8.0$ treatment, APMSF-treated mutant thrombin preparations were passed through a Centricon 10 filter (Amicon Corp., Beverly, MA; molecular weight cutoff of 10,000) which retained the recombinant thrombins and all receptor blocking activity. Flowthroughs were tested in amounts greater than those used in platelet experiments and were found to be devoid of any thrombin-inhibiting activity as measured by thrombin-induced hydrolysis of the fluorogenic thrombin substrate D-phenylalanyl-prolyl-arginyl-7-amino-4-trifluoromethyl coumarin (D-Phe-Pro-Arg-AFC; Enzyme Systems Products, Dublin, CA) even when native thrombin concentrations as low as $1 \mathrm{nM}$ were used (data not shown).

Platelet aggregation and ATP secretion studies. Washed platelets were prepared as previously described (15) and unless otherwise noted were suspended in modified Tyrode's buffer, $\mathrm{pH} 7.4$ with $2 \mathrm{mM}$ magnesium and $1 \mathrm{mM}$ calcium at a concentration of $\sim 3 \times 10^{8}$ platelets $/ \mathrm{ml}$. All platelet studies were performed in a total volume of $500 \mu \mathrm{l}$ with 20 $\mu$ l of Chromolume reagent (Chrono-Log Corp., Havertown, PA). Platelet ATP secretion and aggregation were quantitated independently by measuring changes in luminescence and light transmittance respectively in a dual-channel lumiaggregometer (Chrono-Log Corp.) (16). Stirred platelets were used to ensure rapid and uniform distribution of agonist and initial rates of secretion were determined as defined in the appropriate figure legends.

Voltage-clamped oocyte studies. Xenopus oocytes were harvested from female Xenopus laevis and processed using published techniques $(17,18)$. Individual oocytes were microinjected with cloned functional platelet thrombin receptor cRNA and cultured for $48 \mathrm{~h}$ at $18^{\circ} \mathrm{C}$ in modified Barth's solution (3). Oocytes were voltage clamped at -40 to $-60 \mathrm{mV}$ and agonist-induced inward $\mathrm{Cl}^{-}$currents were measured $(3,19)$.

\section{Results and Discussion}

To determine whether "noncleavable" peptides representing the receptor's cleavage site and thrombin binding domains

1. Abbreviations used in this paper: AFC, amino-4-trifluoromethyl coumarin; APMSF, ( $p$-amidinophenyl)methanesulfonyl fluoride; DIP, diisopropyl fluorophosphate; MES, 2-( $N$-morpholino) ethane sulfonic acid; PPACK, D-Phe-Pro-Arg chloromethyl ketone. could bind thrombin and act as thrombin inhibitors, the peptide LDPRPFLLRNPNDKYEPFWEDEEKNES (peptide 1) was first synthesized. This peptide represents the native receptor sequence encompassing the cleavage recognition sequence LDPR/S and the putative anion-binding exosite binding sequence DKYEPFWEDEE $(3,5,6)$; the serine in the receptor's $\mathrm{Pl}^{\prime}$ position has been replaced by a proline (residue 5 in the peptide) to slow hydrolysis of the peptide by thrombin. As shown in Fig. 1 (left), this peptide was a potent inhibitor of thrombin-induced platelet secretion even when high thrombin concentrations were employed; the $\mathrm{IC}_{50}$ to block $10 \mathrm{nM}$ thrombin was $\sim 400 \mathrm{nM}$ peptide. These data strongly suggest that receptor domains represented within peptide 1 bind thrombin and play an important role in thrombin-receptor interaction.

To determine whether merely interacting with thrombin's small substrate recognition site (i.e., the S1-S4 subsites) could account for the potent antagonist activity of peptide 1 , the shorter peptide LDPRPFLL (peptide 2) was synthesized. This peptide lacks the anion-binding exosite binding domain sequence (DKYEPFWEDEE) found in peptide 1, and was 500fold less potent $\left(\mathrm{IC}_{50}\right.$ for $10 \mathrm{nM}$ thrombin, $\left.200 \mu \mathrm{M}\right)$ than peptide 1 in blocking thrombin-induced platelet activation (Fig. 1, left vs. middle). This result is consistent with the "two site" model of thrombin receptor interaction presented in the introduction, in which recognition of both the receptor's LDPR

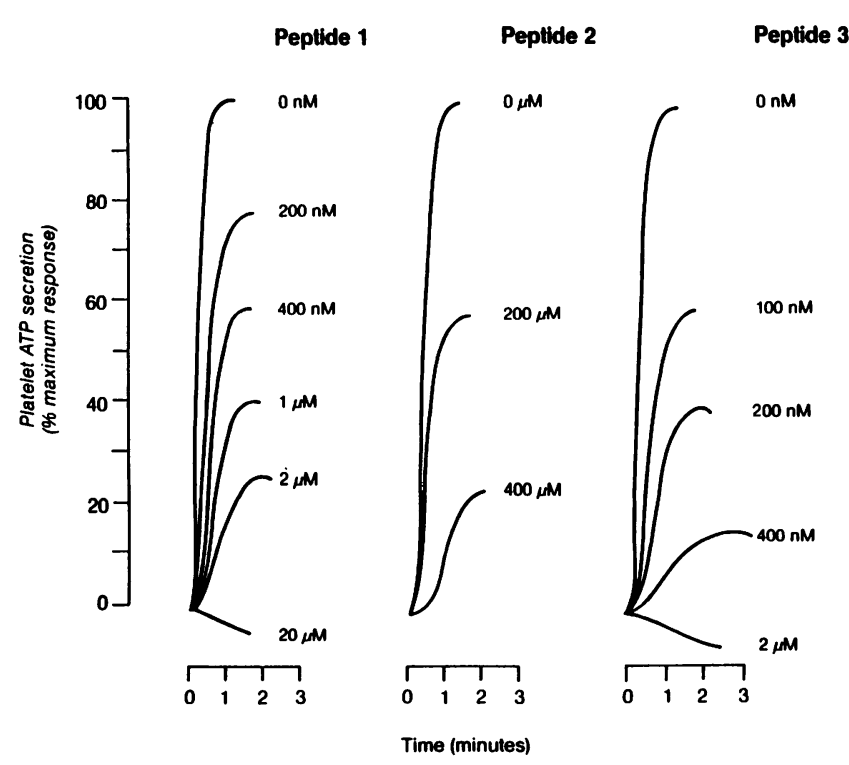

Figure 1. Uncleavable receptor-mimicking peptides block thrombininduced platelet ATP secretion. Thrombin was preincubated for 5 $\mathrm{min}$ at room temperature in the presence or absence of different receptor-mimicking peptides (left, peptide 1, LDPRPFLLRNPNDKYEPFWEDEEKNES; middle, peptide 2, LDPRPFLL; and right, peptide 3, D-Phe-Pro-Arg-PFLLRNPNDKYEPFWEDEEKNES) and then added in a total volume of $20 \mu \mathrm{l}$ of phosphate-buffered saline to $480 \mu$ l of platelets prepared as previously described (15). The final thrombin concentration was $10 \mathrm{nM}$ and the final peptide concentrations were as noted. Platelet ATP secretion was measured in a lumiaggregometer and is expressed as a percentage of the maximal luminescence signal generated by $10 \mathrm{nM}$ thrombin in the absence of inhibitor peptides. These figures are tracings of platelet secretion curves and are representative of the results obtained in three replicate experiments. Qualitatively similar results were obtained when platelet aggregation was used as an end point. 
cleavage recognition sequence and its hirudin-like DKYEPFWEDEE sequence are critical for effective interaction with thrombin.

Because structure activity studies with protein $\mathrm{C}$ have suggested that the LDPR sequence is not an optimal recognition site for cleavage by thrombin (20) and because the sequence D-Phe-Pro-Arg is known to bind to thrombin's S1-S3 subsites effectively (21), we produced a receptor peptide (peptide 3) corresponding to peptide 1 but with the Leu-Asp-Pro-Arg sequence replaced by the sequence D-Phe-Pro-Arg. As shown in Fig. 1 (right), peptide 3 was fourfold more potent than the native sequence peptide 1 in blocking thrombin-induced responses $\left(\mathrm{IC}_{50}\right.$ for $10 \mathrm{nM}$ thrombin, $\left.100 \mathrm{nM}\right)$. This receptorbased peptide is functionally similar to another thrombin-inhibiting peptide, hirulog, in which a D-Phe-Pro-Arg sequence was coupled to the carboxyl tail of hirudin (22). The increase in the inhibitory potency of the receptor-based peptide seen upon replacing the LDPR sequence with D-Phe-Pro-Arg strongly suggests that the amino acids in these positions interact with thrombin's S1-S3 subsites, in agreement with the model presented above.

The specificity of the thrombin receptor-based peptides was shown by their inability to inhibit platelet activation by other agonists. When thrombin was used at its $\mathrm{EC}_{50}$ for platelet activation $(1 \mathrm{nM})$, the $\mathrm{IC}_{50}$ 's for peptides 1,2 , and 3 were $\sim 200$ $\mathrm{nM}, 50 \mu \mathrm{M}$, and $50 \mathrm{nM}$, respectively. These concentrations of peptides had no effect on platelet ATP secretion or aggregation induced by $\mathrm{EC}_{50}$ concentrations of arachidonate, $\mathrm{A} 23187$, or thrombin receptor agonist peptide SFLLRNPNDKYEPF. The latter mimics the receptor amino terminus unmasked upon receptor cleavage by thrombin, thereby bypassing the cleavage step to directly activate the receptor (3). These data demonstrate that "noncleavable" peptides representing the receptor domains postulated to interact with thrombin do indeed function as specific thrombin inhibitors with a rank order of potency predicted by the structure-activity relationships outlined above.

If a noncleavable receptor-based peptide could function as a thrombin inhibitor by binding thrombin and preventing its interaction with the thrombin receptor, a proteolytically inert thrombin might be predicted to function as a receptor antagonist by binding to the receptor and blocking its interaction with native thrombin. Based on the two-site model of thrombin-receptor interaction presented above, we particularly wanted a proteolytically inactive thrombin in which both the active site/ S1-S4 subsite region and the anion-binding exosite region had preserved binding functions. To produce proteolytically inert thrombins with preserved binding functions, recombinant thrombins with amino acid substitutions at the serine protease catalytic triad were created. In thrombin, the serine, histidine, and aspartate residues that participate in catalysis are located at $\beta$-chain positions 205,57 , and 99 , respectively. Craik and colleagues have demonstrated that amino acid substitutions at the analogous active site residues in trypsin abolish trypsin's protease activity without significantly altering its substrate binding properties or crystal structure $(23,24)$. Based on these observations, we produced recombinant thrombin mutants containing the single amino acid substitution of alanine for serine at $\beta$ chain position 205 ("S205A") and the double substitution containing an additional asparagine for aspartate substitution at $\beta$-chain position 99 ("D99N/S205A").
Recombinant native thrombin as well as mutant thrombins S205A and D99N/S205A were produced from the corresponding prothrombins expressed in CHO fibroblasts (8) (see Methods). The specific activity of the recombinant native thrombin could not be distinguished from that of homogeneous, nonrecombinant thrombin by fibrinogen clotting or amidolytic activity using the fluorogenic thrombin substrate D-Phe-Pro-ArgAFC. By contrast, the S205A and D99N/S205A mutant thrombins exhibited no detectable amidolytic or fibrinogen clotting activity, even when mutant thrombin concentrations as high as $400 \mathrm{nM}$ were employed (data not shown). It should be noted that the S205A mutant thrombin differs from native thrombin by only a single oxygen atom.

In contrast to the loss of protease activity caused by the amino acid substitutions at the protease active site, the binding functions of both the active/small substrate binding region and the anion-binding exosite were preserved in the mutant thrombins. The function of the active site/small substrate binding pocket region was examined by assessing the ability of the mutant thrombins to bind benzamidine and D-Phe-Pro-Arg-AFC. Both recombinant native and mutant thrombins retained the ability to bind benzamidine (Fig. 2), a reversible inhibitor of serine proteases which specifically occupies the small substrate binding pocket/S1 subsite (25). The recombinant mutant thrombins were also able to bind and sequester the fluorogenic thrombin substrate D-Phe-Pro-Arg-AFC, thereby blocking its hydrolysis by native thrombin (data not shown). D-Phe-ProArg-AFC occupies thrombin's S1-S3 subsites $(21,26)$. These observations strongly suggest that the active site/S1-S3 subsite region of $\mathbf{S 2 0 5 A}$ thrombin retains binding function. This is in contrast to thrombins rendered proteolytically inactive by chemical modifications of the active site, such as D-Phe-ProArg-chloromethyl ketone (PPACK)- or APMSF-thrombin. The active site/small substrate binding region of these thrombins is occupied and cannot participate in substrate binding $(14,21)$, hence their inability to bind benzamidine (Fig. 2). It is likely that the other binding surfaces on these thrombins, including the anion-binding exosite, remain functional. Nonetheless, the loss of one of two binding surfaces thought to be important in thrombin-receptor interaction in the chemically modified thrombins suggested that the recombinant mutant thrombins might be better thrombin receptor-binding reagents.

Active site-independent binding functions of the S205A mutant thrombin were assessed by examining its ability to bind thrombomodulin. As shown in Fig. 3, S205A thrombin inhibited thrombomodulin-dependent activation of protein $\mathrm{C}$ by wild-type thrombin with an $\mathrm{IC}_{50}$ of $\sim 0.3 \mathrm{nM}$, indistinguishable from that of DIP-thrombin. The potency of the S205A mutant thrombin in competing with native thrombin in this assay suggests that sites required for thrombomodulin binding, including thrombin's anion-binding exosite, remain functional in the mutant thrombin.

To determine whether the active site mutant thrombin was capable of interacting with the cloned thrombin receptor, we examined the ability of S205A mutant thrombin to block thrombin-induced responses in Xenopus oocytes expressing thrombin receptor cRNA (3). As shown in Fig. 3, in oocytes expressing thrombin receptor cRNA, native thrombin elicited a calcium-dependent inward chloride current reflecting an increase in cytosolic calcium, a normal thrombin-induced sec- 


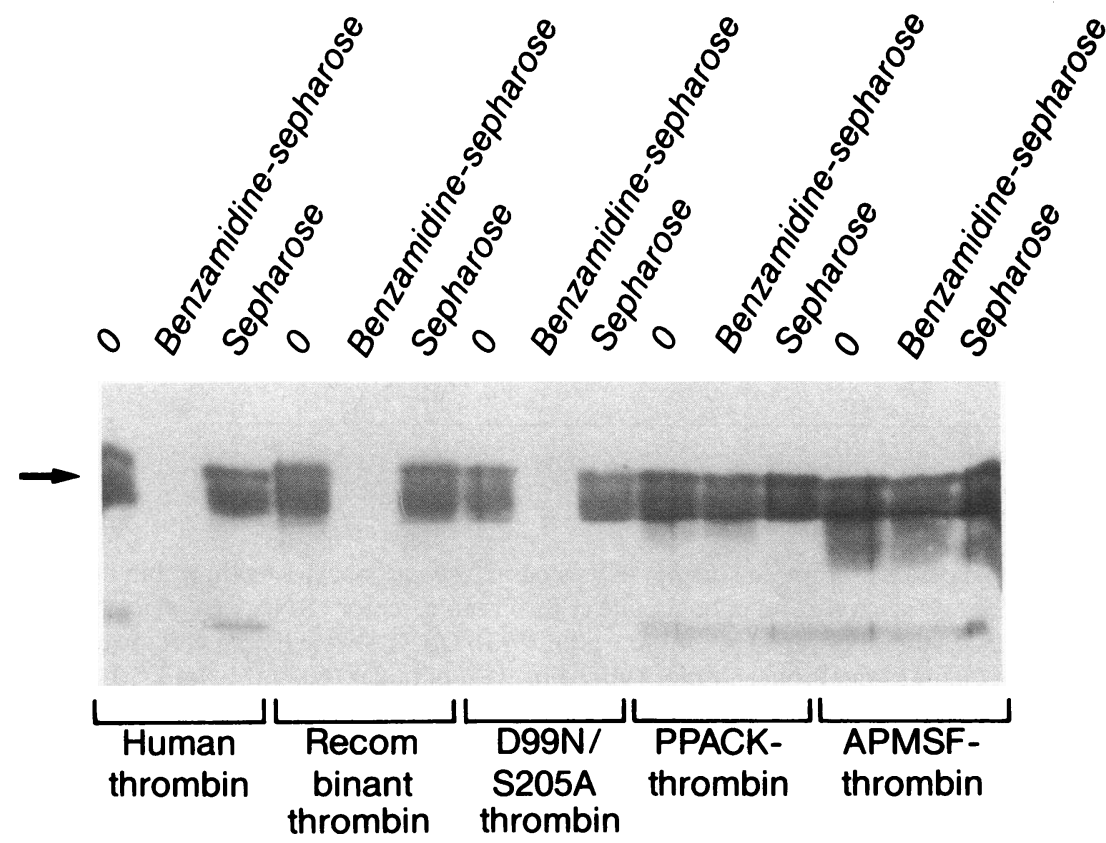

Figure 2. Determination of active site/small substrate binding region function: ability to bind benzamidine beads. Approximately 350 ng nonrecombinant native thrombin (lanes $1-3)$, recombinant native thrombin (lanes 4-6), D99N/S205A mutant thrombin (lanes 7-9), D-Phe-Pro-Arg-chloromethyl ketone (PPACK)-treated thrombin (lanes 10-12) (26), and APMSF-thrombin (lanes 13-15) (14) in $82 \mu \mathrm{l}$ of $170 \mathrm{mM} \mathrm{NaCl}, 10 \mathrm{mM} 2-(N$-morpholino) ethane sulfonic acid (MES), pH 7.4, 0.5\% PEG 6000 were incubated with $36 \mu$ of either $50 \%$ (vol/vol) Sepharose 2B or p-aminobenzamidine-linked Sepharose (Pierce Chemical Co., Rockford, IL) for $3 \mathrm{~h}$ at room temperature. The Sepharose beads were pelleted by centrifugation and the supernatants analyzed by $9 \%$ SDS-PAGE gel electrophoresis under reducing conditions, followed by immunoblot with thrombin antiserum. These results are representative of results obtained in five replicate experiments. S205A mutant thrombin behaved identically to D99N/S205A mutant thrombin with respect to benzamidine binding (data not shown). ond messenger event (3). By contrast, the recombinant S205A mutant thrombin was incapable of inducing an inward current in oocytes expressing the cloned platelet thrombin receptor,

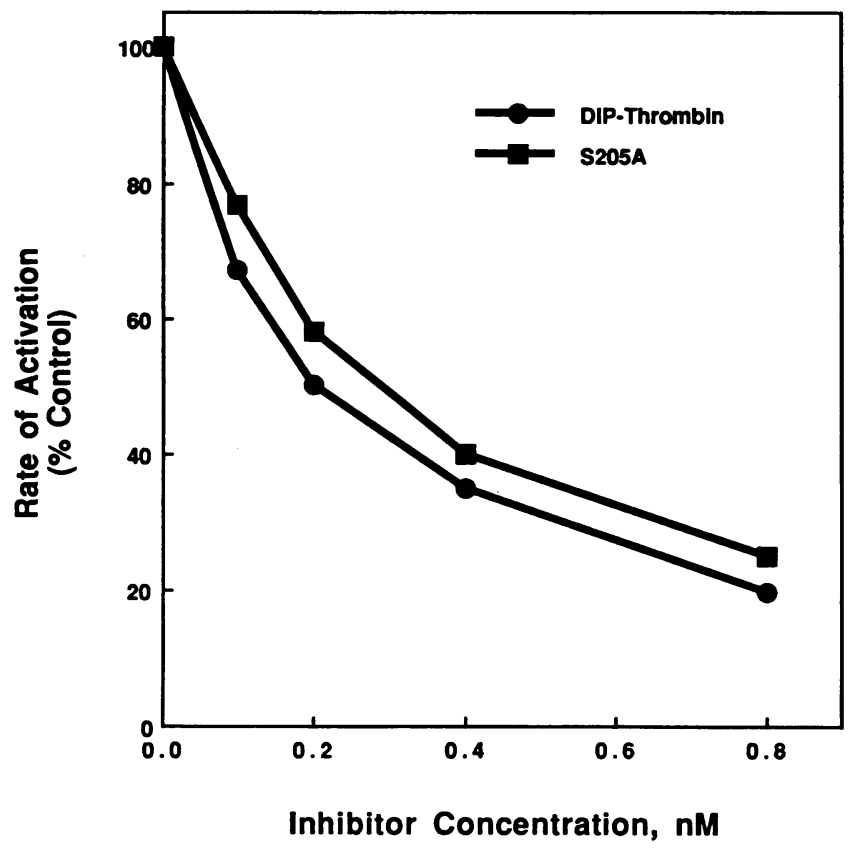

Figure 3. Inhibition of thrombin-thrombomodulin activation of protein C by DIP-thrombin and S205A thrombin. Bovine protein C (1 $\mu \mathrm{M})$ was activated in a solution $(0.1 \mathrm{M} \mathrm{NaCl}, 0.02 \mathrm{M}$ Tris- $\mathrm{HCl}, \mathrm{pH}$ $7.5,5 \mathrm{mM} \mathrm{CaCl}_{2}, 0.1 \%$ gelatin) containing $0.1 \mathrm{nM}$ human thrombin, $0.2 \mathrm{nM}$ rabbit thrombomodulin, and the indicated concentrations of DIP-thrombin (•) or the S205A thrombin mutant (ם). After 30 min at $37^{\circ} \mathrm{C}$, antithrombin III was added to inhibit the thrombin and the activated protein $\mathrm{C}$ generated was measured by its activity vs. the chromogenic substrate S2238 (KabiVitrum, Stockholm, Sweden). The rates of activation are compared to that observed in the absence of inhibitor. even when employed at concentrations as high as $400 \mathrm{nM}$ (Fig. 4). Strikingly, the active site mutant thrombins were potent antagonists of thrombin-induced activation of thrombin receptor-expressing oocytes but did not block oocyte activation by submaximal $\left(\mathrm{EC}_{33}\right)$ concentrations of the thrombin receptor agonist peptide SFLLRNPNDKYEPF (Fig. 4); this peptide mimics the new amino terminus unmasked by thrombin-mediated receptor cleavage and can therefore activate the receptor directly, bypassing the requirement for receptor cleavage (3). These results suggest that the blockade of thrombin receptor activation by S205A thrombin is due to inhibition of receptor proteolysis by native thrombin and not to a more general perturbation of receptor function.

The active site mutant thrombins not only blocked thrombin responses in the oocyte system; they were also effective antagonists of thrombin-induced platelet activation. Preincubation of platelets with the S205A mutant thrombin markedly attenuated both the initial rate (Fig. 5) and extent of thrombininduced platelet secretion (Fig. 6). Preincubation with mutant thrombin caused marked delays in thrombin-induced platelet aggregation as well. The inhibitory activity of these mutant thrombin preparations could be removed by adsorption to benzamidine-Sepharose but not to unsubstituted Sepharose (data not shown), strongly suggesting that the inhibitory activity of the mutant thrombin preparations was due to the recombinant protein itself.

Inhibition of platelet activation by the S205A mutant thrombin was specific for thrombin-induced responses, in that the mutant protein had no effect on platelet secretion induced by submaximal stimulating concentrations of thrombin receptor agonist peptide SFLLRNPNDKYEPF or A23187 (Fig. 7). These data strongly suggest that the S205A mutant thrombin blocks thrombin responses by specifically binding to the platelet thrombin receptor, thereby preventing receptor proteolysis and activation by the wild-type enzyme. The observation that high concentrations of active site mutant thrombin ( $400 \mathrm{nM})$ are required to block thrombin receptor activation by $\mathrm{EC}_{50}$ 

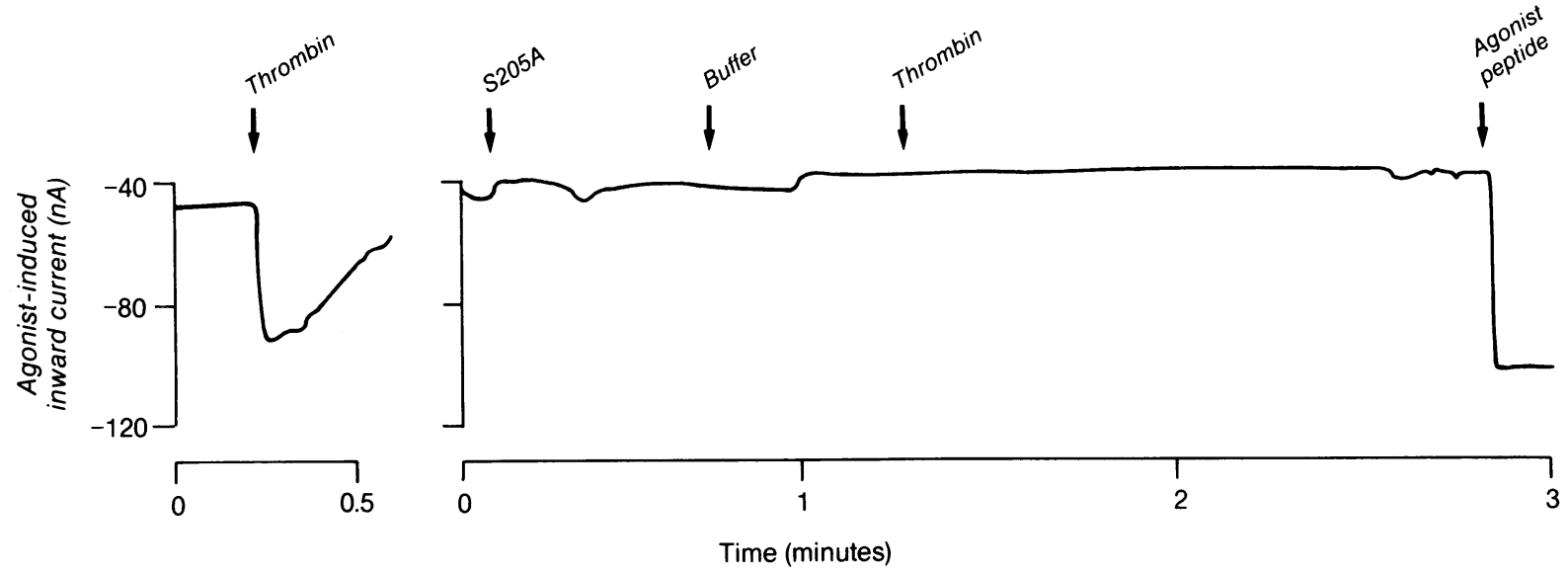

Figure 4. S205A thrombin blocks activation of a cloned functional platelet thrombin receptor expressed in Xenopus oocytes by thrombin but not by agonist peptide SFLLRNPNDKYEPF. Individual oocytes expressing cloned functional platelet thrombin receptor cRNA were placed in individual wells containing $250 \mu \mathrm{l}$ of modified Barth's medium and voltage clamped at -40 to $-60 \mathrm{mV}$ (3). Oocytes were then preincubated for $5 \mathrm{~min}$ at room temperature with either S205A mutant thrombin ( $400 \mathrm{nM}$ final concentration) added in $10 \mu 1$ of buffer $(600 \mathrm{mM} \mathrm{NaCl}, 10 \mathrm{mM}$ MES, pH 6.0, 0.5\% PEG 6000) or an equal volume of buffer alone. Oocytes pretreated with buffer alone (left) responded to $500 \mathrm{pM}$ thrombin with an easily detectable inward current. Pretreatment with S205A thrombin (right) blocked oocyte responses to $500 \mathrm{pM}$ thrombin but did not block responses to submaximal doses $(10 \mu \mathrm{M})$ of agonist peptide SFLLRNPNDKYEPF. Pretreatment with buffer alone had no effect on responses to thrombin or agonist peptide. The current tracings shown in this figure are representative of those obtained in five separate experiments.

concentrations of native thrombin in both platelets and oocytes expressing a functional thrombin receptor is consistent with kinetic predictions for blockade of an irreversible event (i.e., thrombin receptor proteolysis by native thrombin) using a competitive antagonist (i.e. the active site mutant thrombins).
Most efforts to block thrombin-induced platelet activation using chemically modified (DIP, TLCK) thrombins have been unsuccessful $(27,28)$. This is likely due in part to residual agonist activity from incomplete thrombin inactivation by chemical active site blockers (29). In addition, the two-site model of
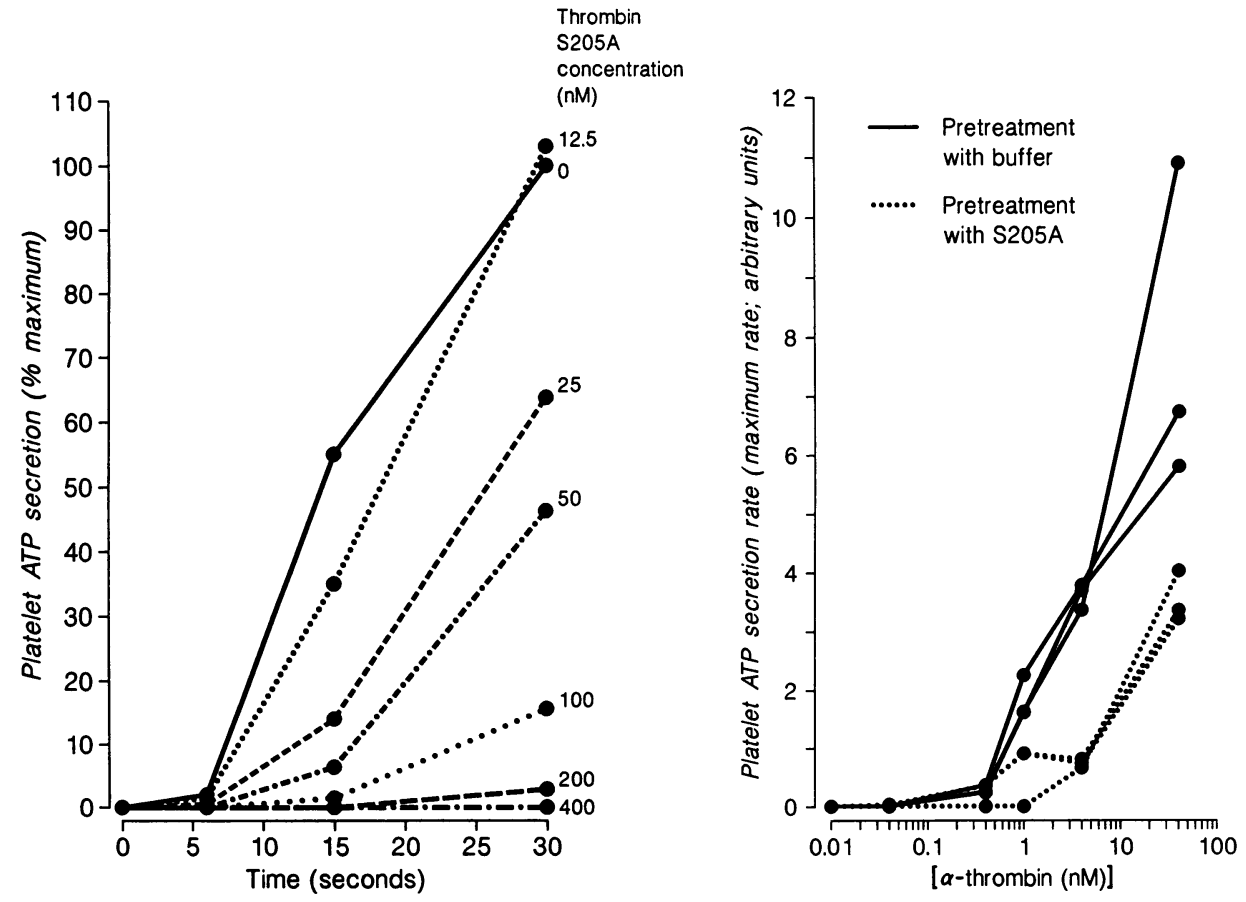

Figure 5. Left: Increasing concentrations of S205A thrombin cause increasing inhibition of thrombin-induced platelet secretion: $500 \mu$ l of washed platelets (14) were incubated for $15 \mathrm{~min}$ at $37^{\circ} \mathrm{C}$ with $18 \mu \mathrm{l}$ of diluted mutant thrombin stocks in 600 $\mathrm{mM} \mathrm{NaCl}, 10 \mathrm{mM}$ MES, pH 6.0, $0.5 \%$ PEG 6000 buffer to give the final concentrations indicated, or $18 \mu \mathrm{l}$ of buffer alone and then challenged with native thrombin ( $1 \mathrm{nM}$ final concentration). Platelet ATP secretion and aggregation were followed for $30 \mathrm{~s}$ after thrombin addition. Platelet ATP secretion data are expressed as a percentage of maximum; $100 \%$ ATP secretion was defined as the luminescence signal obtained $30 \mathrm{~s}$ after addition of $1 \mathrm{nM}$ native thrombin to buffer-pretreated platelets. Each point represents the mean of three replicate determinations. These results are representative of three replicate experiments. Similar results were obtained using the D99N/S205A mutant

thrombin (data not shown). Right: $400 \mathrm{nM} \mathrm{S205A}$ thrombin right-shifts the dose response of platelets to native thrombin by $\sim 1$ log: $18 \mu$ l of mutant thrombin (dotted lines) in $600 \mathrm{mM} \mathrm{NaCl}, 10 \mathrm{mM}$ MES, pH 6.0, 0.5\% PEG 6000 buffer (to give a final mutant thrombin concentration of $400 \mathrm{nM}$ ) or an equal volume of buffer alone (solid lines) were incubated with $500 \mu \mathrm{l}$ of platelets for $15 \mathrm{~min}$ at $37^{\circ} \mathrm{C}$. Platelets were then stimulated with the indicated final concentrations of $\alpha$-thrombin; platelet ATP secretion and aggregation were followed for $30 \mathrm{~s}$ after thrombin addition. The data shown reflect the maximum initial rate of platelet ATP secretion, specifically, the maximum rate of platelet ATP secretion occurring within $30 \mathrm{~s}$ of agonist addition and before any aggregation was detected. Thus the platelet ATP secretion rates reported represent only agonist-induced and not aggregation-induced responses (16). Curves from three replicate experiments are shown. One arbitrary unit corresponds to 33 pmol of ATP released per second based on calibration with ATP standards. 


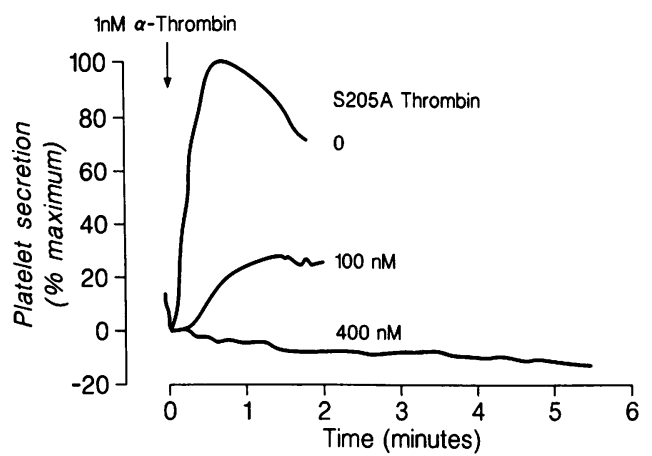

Figure 6. S205A thrombin inhibits the extent of native thrombin-induced platelet secretion. Platelets were preincubated with the indicated concentrations of mutant thrombin as described in the legend to Fig. 4, then stimulated with native thrombin ( $1 \mathrm{nM}$ final concentration). To prevent aggregation-induced secretion, platelets in these experiments were suspended to a final concentration of $2 \times 10^{7}$ platelets $/ \mathrm{ml}$ and were not stirred after the addition of native thrombin. Under these conditions, platelets did not aggregate but did secrete ATP in response to thrombin. Platelet secretion rate is expressed in arbitrary units as defined in the legend to Fig. 4. These figures are tracings of platelet secretion curves, and are representative of the results obtained in three replicate experiments. The decrease in luminescence seen in the control curve (0) is characteristic of the assay and may represent end-product inhibition of luciferase (16).

thrombin-receptor interaction proposed above predicts that loss of the active site/S1-S3 subsite binding determinant upon chemical modification leaves only the thrombin anion-binding exosite available for interaction with the thrombin receptor, thereby decreasing receptor binding. The observation that DIP- and TLCK-thrombins bind to cells identically to native thrombin suggests that most thrombin-binding sites detected by classical binding studies are unrelated to the functional

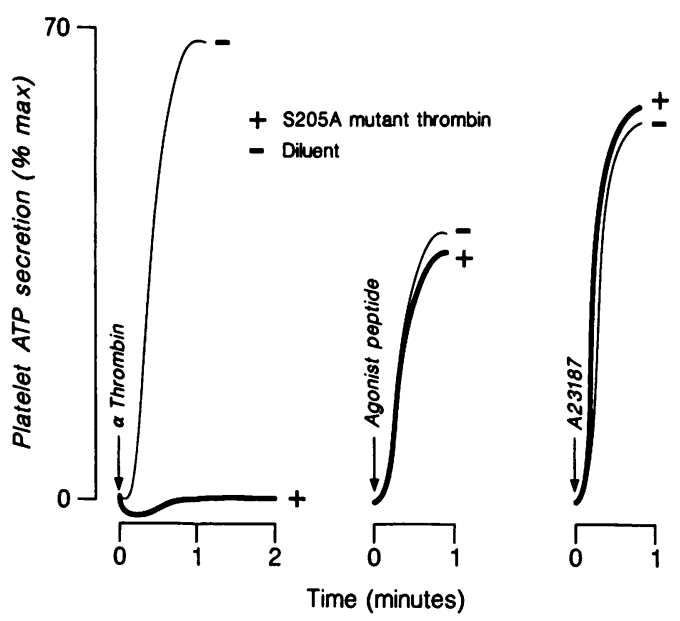

Figure 7. S205A thrombin specifically blocks thrombin-induced platelet ATP secretion. Platelets were preincubated with $400 \mathrm{nM}$ S205A thrombin $(+)$ or buffer $(-)$ as described in the legend to Fig. 4 and then stimulated with native thrombin ( $1 \mathrm{nM}$ final concentration, left), thrombin receptor agonist peptide SFLLRNPNDKYEPF (50 $\mu \mathrm{M}$ final concentration, middle), and A23187 (1 $\mu \mathrm{M}$ final concentration, right). Platelet ATP secretion was measured in a lumiaggregometer and is expressed as a percentage of the mean maximum luminescence signal generated by $100 \mathrm{nM}$ thrombin in the absence of S205A thrombin. These figures are tracings of platelet secretion curves and are representative of the results obtained in three replicate experiments. thrombin receptor (see below). In contrast to DIP- and TLCKthrombins, PPACK-thrombin has been reported to block thrombin-induced platelet activation when used at high concentration (29). This difference may be due to the higher efficiency of thrombin inactivation by PPACK (29) and suggests that occupancy of thrombin's S1-S3 subsites does not abolish all ability to interact with the thrombin receptor. Indeed, a peptide representing only the receptor's anion-binding exosite binding domain has been shown to bind thrombin with a $K_{\mathrm{d}}$ of $\sim 32 \mu \mathrm{M}(6)$. To date, we have not been able to directly study receptor-dependent binding of the recombinant mutant thrombins to either platelets or thrombin receptor-expressing oocytes or mammalian cell lines because of the preponderance of high-affinity thrombin binding sites unrelated to the cloned receptor (glycoprotein Ib in platelets, protease nexins, or other proteins in oocytes and mammalian cells). However, the observation that peptides based on receptor sequence can interact with thrombin and block its function (Fig. 1) as well as recent studies demonstrating the binding of receptor peptides to thrombin (6) provides independent evidence for direct interactions between thrombin and the thrombin receptor's amino terminal extension.

In summary, we have designed two groups of thrombin receptor antagonists based on structure-activity studies of a cloned functional platelet thrombin receptor: $(a)$ "uncleavable" receptor-mimicking peptides designed to bind thrombin, preventing thrombin's interaction with its receptor and other substrates, and $(b)$ proteolytically inert mutant thrombins designed to bind but not activate the thrombin receptor, thereby preventing receptor interaction with native thrombin. The effectiveness of the "uncleavable" receptor-based thrombin-inhibiting peptides is consistent with the proteolytic model of thrombin receptor activation, and the differing potencies of these peptides support the model that thrombin directly interacts with both the receptor's cleavage recognition site LDPR/S and its anion-binding exosite binding sequence DKYEPFWEDEE. The potency of these receptor-based peptides in blocking thrombin-induced platelet activation also supports the hypothesis that the cloned thrombin receptor mediates platelet activation. The proteolytic mechanism of receptor activation is further supported by the fact that selective elimination of a single oxygen atom from thrombin's active site abolished thrombin's protease and platelet-stimulating activities without impairing any thrombin binding functions measured. Specifically, the S205A mutant thrombin retained the ability to bind but not activate the platelet thrombin receptor as evidenced by its ability to block activation of a functional platelet thrombin receptor expressed in oocytes in addition to blocking thrombin-induced platelet activation. The efficacy of these molecular reagents in blocking thrombin-induced platelet activation and the model of thrombin-receptor interaction supported by these studies provide a basis for novel structure-activity studies of thrombin-receptor interaction using further mutations of the S205A thrombin. Lastly, these studies also suggest possible strategies for the development of new antithrombotic agents; the receptor-mimicking peptides are most promising in this regard.

\section{Acknowledgments}

We thank Dr. John Fenton II (Wadsworth Center/Albany Medical College) for his generous gift of $\alpha$-thrombin, Dr. Mark Davis (Stanford 
Medical Center) for his generous gift of the expression plasmid pBJ1, and Drs. Bruce and Barbara Furie (Tufts-New England Medical Center) for their generous gift of native human prothrombin cDNA used in these studies. We also thank Dr. Charles S. Craik for valuable discussions and Drs. Henry R. Bourne, Marc A. Shuman, Lewis T. Williams, and David J. Julius for their critical review of the manuscript for this article.

This work was supported in part by the Physician-Scientist Award HL0248-01 (Dr. Hung), the Tobacco-Related Disease Research Program of the University of California, HL-44907, and HL-43821 (Dr. Coughlin), and Howard Hughes Medical Institute (Dr. Esmon). This work was done during the tenure of an award from the American Heart Association and SmithKline Beecham to Dr. Coughlin.

\section{References}

1. American Heart Association. 1991. American Heart Association Facts, American Heart Association, Dallas, TX

2. Hanson, S. R., and L. A. Harker. 1988. Interruption of acute platelet-dependent thrombosis by the synthetic antithrombin PPACK. Proc. Natl. Acad. Sci. USA. 85:3184-3188.

3. Vu, T.-K. H., D. T. Hung, V. I. Wheaton, and S. R. Coughlin. 1991. Molecular cloning of a functional thrombin receptor reveals a novel proteolytic mechanism of receptor activation. Cell. 64:1057-1068.

4. Rydel, T. J., K. G. Rabichandran, A. Tulinsky, W. Bode, R. Huber, C. Roitsch, and J. W. Fenton II. 1990. The structure of a complex of recombinant hirudin and human alpha-thrombin. Science (Wash. DC). 249:277-280.

5. Vu, T.-K. H., V. I. Wheaton, D. T. Hung, I. Charo, and S. R. Coughlin. 1991. Domains specifying thrombin-receptor interaction. Nature (Lond.). In press.

6. Liu, L.-W., T.-K. H. Vu, C. T. Esmon, and S. R. Coughlin. 1991. The region of the thrombin receptor resembling hirudin binds to thrombin and alters enzyme specificity. J. Biol. Chem. 266:16977-16980.

7. Kunkel, T. A., J. D. Roberts, and R. A. Zakour. 1987. Rapid and efficient site-specific mutagenesis without phenotypic selection. Methods Enzymol. 154:367-382.

8. Jorgensen, M. J., A. B. Cantor, B. C. Furie, and B. Furie. 1987. Expression of completely $\gamma$-carboxylated recombinant human prothrombin. J. Biol. Chem. 262:6729-6734

9. Takebe, Y., M. Seiki, J.-I. Fujisawa, P. Hoy, K. Yokota, K.-I. Arai, M. Yoshida, and N. Arai. 1988. SR $\alpha$ promoter: An efficient and versatile mammalian cDNA expression system composed of the simian virus $\mathbf{4 0}$ early promoter and the R-U5 segment of human T-cell leukemia virus type I long terminal repeat. Mol. Cell. Biol. 8:466-472.

10. Felgner, P. L., T. R. Gadek, M. Holm, R. Roman, H. W. Chan, M. Wenz, J. P. Northrop, G. M. Ringold, and M. Danielsen. 1987. Lipofection: a highly efficient, lipid-mediated DNA-transfection procedure. Proc. Natl. Acad. Sci. USA. 84:7413-7417.

11. Subramani, S., R. Mulligan, and P. Berg. 1981. Expression of the mouse dihydrofolate reductase complementary deoxyribonucleic acid in simian virus 40 vectors. Mol. Cell. Biol. 1:854-864.
12. Fenton, J. W., II, M. J. Fasco, and A. B. Stackrow. 1977. Human thrombins. J. Biol. Chem. 252:3587-3598.

13. Krishnaswamy, S., W. R. Church, M. E. Nesheim, and K. G. Mann. 1987. Activation of human prothrombin by human prothrombinase. J. Biol. Chem. 262:3291-3299.

14. Laura, R., D. J. Robinson, and D. H. Bing. 1980. (p-Amidinophenyl)methanesulfonyl fluoride, an irreversible inhibitor of serine proteases. Biochemistry. 19:4859-4864.

15. Baenzinger, N. G., and P. W. Majerus. 1974. Isolation of human platelets and platelet surface membranes. Methods Enzymol. 31:149-155.

16. Charo, I. F., R. D. Feinman, and T. C. Detwiler. 1977. Interrelations of platelet aggregation and secretion. J. Clin. Invest. 63:866-873.

17. Coleman, A. 1984. Translation of eukaryotic mRNA in Xenopus oocytes. In Transcription and Translation: A Practical Approach. B. D. Hames and S. J. Higgins, editors. IRL Press, Oxford. 271-302.

18. Williams, J. A., D. J. McChesney, M. C. Calayag, V. R. Lingappa, and C. D. Logsdon. 1988. Expression of receptors for cholecystokinin and other $\mathrm{Ca}^{2+}$ mobilizing hormones in Xenopus oocytes. Proc. Natl. Acad. Sci. USA. 85:49394943.

19. Julius, D., A. B. MacDermott, R. Axel, and T. M. Jessel. 1988. Molecular characterization of a functional cDNA encoding the serotonin 1c receptor. Science (Wash. DC). 241:558-563.

20. Erlich, H. J., B. W. Grinnell, S. R. Jaskunas, C. T. Esmon, S. B. Yan, and N. U. Bang. 1990. Recombinant human protein C derivatives: altered response to calcium resulting in enhanced activation by thrombin. EMBO (Eur. Mol. Biol. Organ.) J. 9:2367-2373.

21. Bode, W., I. Mayr, U. Baumann, R. Huber, S. R. Stone, and J. Hofsteenge. 1989. The refined $1.9 \AA$ crystal structure of human $\alpha$-thrombin: interaction with D-phe-pro-arg-chloromethylketone and significance of the tyr-pro-pro-trp insertion segment. EMBO (Eur. Mol. Biol. Organ.) J. 8:3467-3475.

22. Maraganore, J. M., P. Bourdon, J. Jablonski, K. L. Ramachandran, and J. W. Fenton II. 1990. Design and characterization of hirulogs: a novel class of bivalent peptide inhibitors of thrombin. Biochemistry. 29:7095-7101.

23. Higaki, J. N., B. W. Gibson, and C. S. Craik. 1987. Evolution of catalysis in the serine proteases. Cold Spring Harbor Symp. Quant. Biol. 52:615-621.

24. Sprang, S., T. Standing, R. J. Fletterick, R. M. Stroud, J. Finer-Moore, N-H. Xuong, R. Hamlin, W. J. Rutter, and C. S. Craik. 1987. The three-dimensional structure of asn 102 mutant of trypsin: role of asp102 in serine protease catalysis. Science (Wash. DC). 232:905-909.

25. Bode, W., D. Turk, and J. Stürzebecher. 1990. Geometry of binding of the benzamidine- and arginine-based inhibitors $N^{a}$-(2-naphthyl-sulfonyl-glycyl)-DLp-amidinophenylalanyl-piperidine (NAPAP) and (2R,4R)-4-methyl-1-[ $N^{a}-(3-$ methyl-1,2,3,4-tetrahydro-8-quinolinesulphonyl)-1-arginyl]-2-piperidinecarboxylic acid (MQPA) to human $\alpha$-thrombin. Eur. J. Biochem. 193:175-182.

26. Kettner, C., and E. Shaw. 1979. D-phe-pro-argC $\mathrm{CH}_{2} \mathrm{Cl}$ : a selective affinity label for thrombin. Thrombosis Res. 14:969.

27. Tollefsen, D. M., J. R. Feagler, and P. W. Majerus. 1974. The binding of thrombin to the surface of human platelets. J. Biol. Chem. 249:2646-2651.

28. Harmon, J. T., and G. A. Jamieson. 1986. Activation of platelets by $\alpha$-thrombin is a receptor-mediated event. J. Biol. Chem. 261:15928-15933.

29. Greco, N. J., T. E. Tenner Jr., N. N. Tandron, and G. A. Jamieson. 1990. PPACK-thrombin inhibits thrombin-induced platelet aggregation and cytoplasmic acidification but does not inhibit platelet shape change. Blood. 75:19831990. 